\title{
Exposure to plasticizers in German daycare centers: the LUPE 3 study
}

\author{
H. Fromme ${ }^{1}$, T. Lahrz ${ }^{2}$, M. Kraft ${ }^{3}$, A. L. Fembacher ${ }^{1}$, \\ A. Schütze ${ }^{4}$, S. Dietrich ${ }^{1}$, S. Sievering ${ }^{3}$, R. Burghardt ${ }^{2}$, \\ H. M. Koch ${ }^{4} \&$ W. Völkel ${ }^{1}$ \\ ${ }^{1}$ Bavarian Health and Food Safety Authority, Germany \\ ${ }^{2}$ Berlin-Brandenburg State Laboratory, Germany \\ ${ }^{3}$ North Rhine-Westphalia State Agency for Nature, Environment and \\ Consumer Protection, Germany \\ ${ }^{4}$ Institute for Prevention and Occupational Medicine of the German \\ Social Accident Insurance, Germany
}

\begin{abstract}
Plasticizers have been widely used for decades in diverse applications. Therefore indoor air and settled dust samples from 63 daycare centers in Germany were analyzed for the presence of 11 phthalate diesters, 4 adipates, di-isononyl cyclohexane-1,2-dicarboxylate (DINCH), di(2-ethylhexyl) terephthalate (DEHT), acetyl tri- $n$-butyl citrate (ATBC), and trioctyl trimellitate (TOTM). 10 primary and secondary phthalate metabolites were quantified in urine samples of 663 children (1.7 to 6.7 years old) after they attended the facilities. Moreover, 4 metabolites of DINCH were quantified in urine samples of 208 children.

Di-isobutyl phthalate (DiBP), dibutyl phthalate (DnBP), di-2-ethylhexyl phthalate (DEHP), and DINCH were present in the highest concentrations in the indoor air, with median values of $468,227,194$, and $108 \mathrm{ng} / \mathrm{m}^{3}$, respectively. In dust, median values of $888 \mathrm{mg} / \mathrm{kg}$ for DEHP, $302 \mathrm{mg} / \mathrm{kg}$ for DINCH, and 302 $\mathrm{mg} / \mathrm{kg}$ for di-isononyl phthalate (DiNP) were detected.

The highest median values observed in urine were $44.7 \mu \mathrm{g} / \mathrm{l}$ for the monoester of DiBP, $32.4 \mu \mathrm{g} / \mathrm{l}$ for that of DnBP, and $16.5 \mu \mathrm{g} / \mathrm{l}$ and $17.9 \mu \mathrm{g} / \mathrm{l}$ for the two secondary DEHP metabolites. The three secondary metabolites of DINCH were observed with median values between 1.1 and $1.7 \mu \mathrm{g} / \mathrm{l}$.
\end{abstract}


Compared with recommended tolerable daily intake (TDI) values, especially DiBP and DnBP reached a higher proportion of TDI.

Keywords: phthalates, DEHP, DINCH, DEHT, adipates, indoor, human biomonitoring.

\section{Introduction}

Phthalate esters have been widespread in technical applications for decades and are a class of substances consisting of a phthalic acid combined with variablelength alkyl side chains. Due to their physicochemical properties, dialkylated phthalates have been used as plasticizers to soften consumer products and make them more flexible and resilient. In particular, the high-volume chemicals di-2ethylhexyl phthalate (DEHP), dibutyl phthalate (DnBP), benzyl butyl phthalate (BzBP), di-isononyl phthalate (DiNP), and di-isodecyl phthalate (DiDP) can be found in diverse applications, including pharmaceutical products, cosmetics, construction materials, wood finishers, adhesives, floorings, paints, medical devices, and, primarily, as plasticizers in PVC production. Meanwhile, DEHP, DnBP and BzBP are subject to restriction by the REACH Annex XIV, which places restrictions on the marketing of and prohibits the use of these substances. Particularly due to the ongoing scientific debate of the health risks and subsequent regulation of short-chain phthalates these phthalates have been continuously replaced by longer chain phthalates, such as DiNP and DiDP. Additionally, "new" substances, such as di-isononyl cyclohexane-1,2-dicarboxylate (DINCH), $\operatorname{di}(2-$ ethylhexyl) terephthalate (DEHT) and di(2-ethylhexyl) adipate (DEHA), which exhibit a considerably more favorable toxicological profile, have been substituted for the phthalates.

The aim of this study was to investigate the exposure of certain phthalates and non-phthalate plasticizers in daycare centers in Germany (see Table 1). Overall, 19 plasticizers were quantified in the indoor air and settled dust and 14 primary and secondary metabolites of these substances were measured in the urine of children attending daycare centers. The total exposure of the children was quantified using a back-calculation approach from the excreted metabolites and was compared with toxicological values.

This study is one sub-project performed by health authorities of some German Bundesländer (Länderuntersuchungsprogramme, LUPE) to characterize the exposure of a vulnerable subset of the population and to develop strategies to minimize the current exposure to these substances. Results of organophosphates in indoor air and dust as well as their metabolites have been previously reported $[1,2]$.

\section{Methods}

The indoor air samples were collected on a cartridge with a glass fiber filter and on polyurethane foam using a sampler with a constant air flow of $3.5 \mathrm{l} / \mathrm{min}$ over approximately 6 hours. Settled dust samples were collected by slowly vacuuming 
Table 1: Plasticizers and metabolites measured in this study.

\begin{tabular}{|c|c|c|c|}
\hline Substance & Abbr. & Metabolite & Abbr. \\
\hline Dimethyl phthalate & DMP & 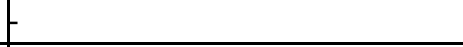 & 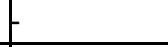 \\
\hline Diethyl phthalate & DEP & Mono-ethyl phthalate & MEP \\
\hline Di-n-butyl phthalate & DnBP & Mono-n-butyl phthalate & $\mathrm{MnBP}$ \\
\hline Di-isobutyl phthalate & DiBP & Mono-isobutyl phthalate & MiBP \\
\hline Di-n-pentyl phthalate & DnPP & Mono-4-hydroxypentyl phthalate & MHPP \\
\hline Di-isopentyl phthalate & DiPP & Mono-isopentyl phthalate & MiPP \\
\hline Dicyclohexyl phthalate & DcHP & 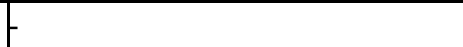 & t \\
\hline Benzylbutyl phthalate & BzBP & Mono-benzyl phthalate & MBzP \\
\hline $\begin{array}{l}\text { Di-2-ethylhexyl } \\
\text { phthalate }\end{array}$ & DEHP & $\begin{array}{l}\text { Mono-(2-ethyl-5-oxohexyl) } \\
\text { phthalate } \\
\text { Mono-(2-ethyl-5-hydroxyhexyl) } \\
\text { phthalate }\end{array}$ & $\begin{array}{l}\text { 5охо-МЕНР } \\
\text { 5ОН-МЕНР }\end{array}$ \\
\hline Di-isononyl phthalate & DiNP & $\begin{array}{l}\text { Mono-4-methyl-7-oxo-octyl } \\
\text { phthalate }\end{array}$ & 7oxo-MiNP \\
\hline Di-isodecyl phthalate & DiDP & $\begin{array}{l}\text { Mono(4,5-dimethyl-7- } \\
\text { hydroxyoctyl) phthalate }\end{array}$ & $\mathrm{OH}-\mathrm{MiDP}$ \\
\hline $\begin{array}{l}\text { Di-iso-nonyl-1,2- } \\
\text { cyclohexanedi- } \\
\text { carboxylate }\end{array}$ & DINCH & $\begin{array}{l}\text { cyclohexane-1,2-dicarboxylic acid } \\
\text { monoisononyl ester } \\
\text { cyclohexane-1,2-dicarboxylic acid- } \\
\text { mono(hydroxy-isononyl) ester } \\
\text { cyclohexane-1,2-dicarboxylic acid- } \\
\text { mono(carboxy iso-octyl) ester } \\
\text { cyclohexane-1,2-dicarboxylic acid } \\
\text { mono(oxo-isononyl) ester }\end{array}$ & $\begin{array}{l}\text { MINCH } \\
\text { oH-MINCH } \\
\text { oxo-MINCH }\end{array}$ \\
\hline Acetyltri-n-butyl citrate & ATBC & - & \\
\hline $\begin{array}{l}\text { Di(2-ethylhexyl) } \\
\text { adipate }\end{array}$ & DEHA & - & \\
\hline Di-n-butyl adipate & DnBA & 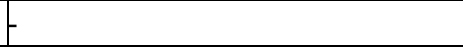 & \\
\hline Di-iso-butyl adipate & DiBA & - & \\
\hline Di-iso-nonyl adipate & DiNA & - & \\
\hline $\begin{array}{l}\text { Di(2-ethylhexyl) } \\
\text { terephthalate }\end{array}$ & DEHT & & \\
\hline $\begin{array}{l}\text { Tri(2-ethylhexyl) } \\
\text { trimellitate }\end{array}$ & TOTM & & \\
\hline
\end{tabular}

the floor of the room during a fixed time period using an ALK dust filter holder mounted on a sampler connected to a vacuum cleaner. After extraction the analysis of air and dust samples was performed on a gas chromatographic system with mass selective detector (GC-MS). For urine samples the analytical method consisted of an offline protein precipitation followed by HPLC and MS/MS detection using a column switching LC-MS/MS unit. 


\section{Results}

\subsection{Indoor air}

The results are given in Table 2. We were able to detect DMP, DEP, DBP, DiBP, and DEHP in $95 \%$ to $98 \%$ of the samples above the LOQ, as well as DiNP in $92 \%$, DiDP in $38 \%$, BzBP in $10 \%$, and DcHP in $6 \%$ of the samples above the LOQ. DnPP could not be quantified in any sample. DEHA, DEHT, and DINCH were quantified in $85 \%, 85 \%$, and $76 \%$ of the samples, respectively. The median values were $468 \mathrm{ng} / \mathrm{m}^{3}$ for DiBP, $227 \mathrm{ng} / \mathrm{m}^{3}$ for DBP, $194 \mathrm{ng} / \mathrm{m}^{3}$ for DEHP, $183 \mathrm{ng} / \mathrm{m}^{3}$ for DEP, $102 \mathrm{ng} / \mathrm{m}^{3}$ for DiNP, and $76 \mathrm{ng} / \mathrm{m}^{3}$ for DMP. The highest maximum values were seen for DiBP, DMP, and DnBP, with concentrations of 2600, 1400, and 1300 , respectively. For the three substitutes, the median values were 20 (DEHT), 34 (DEHA), and $108 \mathrm{ng} / \mathrm{m}^{3}$ (DINCH).

\subsection{House dust}

The statistical parameters for the phthalate measurements in dust from daycare centers are provided in Table 2. DEP, DiBP, DnBP, DEHP, DiNP, and DiDP were detected in 100\%, DMP and BzBP in 95\%, DPhP and DcHP in $79 \%$, and DnOP in $65 \%$ of the house dust samples. The median values were $888 \mathrm{mg} / \mathrm{kg}$ (DEHP), $302 \mathrm{mg} / \mathrm{kg}$ (DiNP), $34 \mathrm{mg} / \mathrm{kg}$ (DiDP), $21 \mathrm{mg} / \mathrm{kg}$ (DBP), $21 \mathrm{mg} / \mathrm{kg}$ (DnBP), 20 $\mathrm{mg} / \mathrm{kg}$ (DiBP), $6 \mathrm{mg} / \mathrm{kg}$ (BzBP), $1.3 \mathrm{mg} / \mathrm{kg}$ (DEP), $0.7 \mathrm{mg} / \mathrm{kg}$ (DMP), and 0.3 $\mathrm{mg} / \mathrm{kg}$ (DcHP). In particular, DEHP and DiNP varied widely, and high maximum values of $10086 \mathrm{mg} / \mathrm{kg}$ and $7091 \mathrm{mg} / \mathrm{kg}$ were observed for DEHP and DiNP, respectively. DnPP and DPrP were detected in only 13 and 9 samples with maximum values of $0.7 \mathrm{mg} / \mathrm{kg}$ and $0.6 \mathrm{mg} / \mathrm{kg}$, respectively. The three other plasticizers analyzed were detected in all samples above the LOQ except DEHA (only in 62 samples), and median concentrations of $302 \mathrm{mg} / \mathrm{kg}$ for DINCH, 40 $\mathrm{mg} / \mathrm{kg}$ for DEHT, and $49 \mathrm{mg} / \mathrm{kg}$ were found. Again, the results, especially for $\mathrm{DINCH}$, varied over a wide range.

\subsection{Metabolites in urine samples}

In Table 3 the results are given. MnBP, MiBP, 5OH-MEHP, and 5oxo-MEHP were detected in 100\%, 7oxo-MiNP in 98\%, MBzP in $82 \%$, MEP in $67 \%$, and $\mathrm{OH}-\mathrm{MiDP}$ in $30 \%$ of all 663 samples collected after daycare attendance. MnOP and MiPP were found in only 6 and 2 samples, with maximum values of 1.8 and $6.1 \mu \mathrm{g} / 1$, respectively. MHPP, a secondary metabolite of DnPP, was not detected in any sample. As can be seen in Table 3, the highest median values were observed for $\operatorname{MiBP}(44.7 \mu \mathrm{g} / \mathrm{l}), \mathrm{MnBP}(32.4 \mu \mathrm{g} / \mathrm{l})$, and the two secondary DEHP metabolites ( $16.5 \mu \mathrm{g} / 1$ for $5 \mathrm{OH}-\mathrm{MEHP}$ and $17.9 \mu \mathrm{g} / 1$ for 5oxo-MEHP). Overall, the readings ranged over several orders of magnitude, with the highest maximum values of $5225 \mu \mathrm{g} / 1$ for MEP and $2063 \mu \mathrm{g} / 1$ for MnBP. In addition, 5OH-MEHP, 5oxoMEHP, 7oxo-MiNP, and MBzP were found in significantly higher concentrations in males. No significant differences were observed among the three age groups. 
Table 2: Plasticizers in indoor air and house dust of 63 daycare centers.

\begin{tabular}{|c|c|c|c|c|c|}
\hline $\begin{array}{l}\text { Com- } \\
\text { pound }\end{array}$ & $\mathrm{N}>\mathrm{LOQ}$ & Mean & Min-Max & Median & $\begin{array}{c}95^{\text {th }} \\
\text { percentile }\end{array}$ \\
\hline \multicolumn{6}{|c|}{ Dust (mg/kg) } \\
\hline DMP & 60 & 0.7 & $<0.04-11$ & 0.3 & 2.4 \\
\hline DEP & 63 & 3.4 & $0.4-101$ & 1.4 & 7.4 \\
\hline DiBP & 63 & 39 & $7-335$ & 20 & 174 \\
\hline DnBP & 63 & 30 & $2-266$ & 21 & 95 \\
\hline DnPP & 10 & & $<0.1-0.69$ & & \\
\hline BzBP & 60 & 21 & $<1.0-348$ & 6 & 93 \\
\hline DEHP & 63 & 1973 & 99-10086 & 888 & 7616 \\
\hline DcHP & 50 & 5.4 & $<0.03-239$ & 0.3 & 12 \\
\hline DiNP & 63 & 745 & $30-7091$ & 302 & 2955 \\
\hline DiDP & 63 & 60 & $5-571$ & 34 & 170 \\
\hline DINCH & 63 & 504 & $32-2732$ & 302 & 1622 \\
\hline DEHT & 63 & 74 & $9-312$ & 40 & 256 \\
\hline DEHA & 63 & 80 & $1.0-724$ & 49 & 307 \\
\hline DiBA & 25 & & $<0.1-6.0$ & & \\
\hline DnBA & 0 & & & & \\
\hline DiNA & 3 & & $<1-34$ & & \\
\hline ATBC & 40 & 146 & $<8-3314$ & 24 & 407 \\
\hline TOTM & 63 & & $<7-107$ & & \\
\hline \multicolumn{6}{|c|}{ Indoor air $\left(\mathrm{ng} / \mathrm{m}^{3}\right)$} \\
\hline DMP & 60 & 163 & $<0.01-1431$ & 76 & 833 \\
\hline DEP & 62 & 208 & $<0.01-781$ & 183 & 383 \\
\hline DiBP & 60 & 516 & $<0.01-2613$ & 468 & 916 \\
\hline DnBP & 60 & 283 & $<0.01-1276$ & 227 & 884 \\
\hline DnPP & 0 & & & & \\
\hline $\mathrm{BzBP}$ & 6 & & $<0.01-215$ & & \\
\hline DEHP & 61 & 276 & $<0.01-889$ & 194 & 765 \\
\hline DcHP & 2 & & $<0.01-64$ & & \\
\hline DiNP & 58 & 133 & $<0.05-763$ & 102 & 341 \\
\hline DiDP & 24 & 49 & $<0.05-226$ & 25 & 165 \\
\hline DINCH & 48 & 159 & $<0.05-781$ & 108 & 547 \\
\hline DEHT & 54 & 31 & $<0.01-226$ & 20 & 120 \\
\hline DEHA & 54 & 49 & $<0.01-206$ & 34 & 139 \\
\hline DiBA & $37 *$ & 17 & $<0.01-89$ & 35 & 53 \\
\hline DnBA & $41 *$ & 45 & $<0.01-134$ & 91 & 136 \\
\hline DiNA & $0 *$ & & & & \\
\hline ATBC & $27 *$ & 19 & $<0.01-122$ & 45 & 72 \\
\hline TOTM & $0 *$ & & & & \\
\hline
\end{tabular}

Values below the LOQ were assigned half of the LOQ;

*: in a subset of 43 daycare centers. 
Table 3: Phthalate and DICH metabolites in 663 and 208 urine samples in $\mu \mathrm{g} / \mathrm{l}$.

\begin{tabular}{|l|c|c|c|c|c|}
\hline & $\begin{array}{c}\text { N }> \\
\text { LOQ }\end{array}$ & Mean & Median & $\begin{array}{c}9^{\text {th }} \\
\text { percentile }\end{array}$ & Min-Max \\
\hline \multicolumn{7}{|c|}{ Phthalate metabolites } \\
\hline MEP & 443 & 34.9 & 14.5 & 112 & $<2.5-5225$ \\
\hline MnBP & 663 & 42.6 & 32.4 & 124 & $2.3-221$ \\
\hline MiBP & 663 & 64.4 & 44.7 & 155 & $2.1-2063$ \\
\hline MBzP & 543 & 20.2 & 11.6 & 80.7 & $<2.5-311$ \\
\hline 5OH-MEHP & 663 & 22.5 & 16.5 & 60.2 & $0.8-225$ \\
\hline 5oxo-MEHP & 663 & 23.1 & 17.9 & 58.2 & $0.8-168$ \\
\hline 7oxo-MiNP & 648 & 10.5 & 4.6 & 29.9 & $<0.5-486$ \\
\hline OH-MiDP & 199 & 2.8 & 0.8 & 8.6 & $<1.3-155$ \\
\hline \multicolumn{7}{|c|}{ DINCH metabolites } \\
\hline MINCH & 47 & $<0.1$ & $<0.1$ & 0.41 & $<0.10-2.0$ \\
\hline OH-MINCH & 208 & 2.87 & 1.66 & 9.95 & $0.14-34.9$ \\
\hline cx-MINCH & 208 & 1.89 & 1.14 & 6.11 & $0.11-19.1$ \\
\hline oxo-MINCH & 206 & 2.54 & 1.54 & 7.98 & $<0.05-34.8$ \\
\hline
\end{tabular}

Values below the LOQ were assigned half of the LOQ.

Secondary DINCH metabolites $\mathrm{OH}-\mathrm{MINCH}$ and cx-MINCH were quantified in all samples, while oxo-MINCH and monoester $\mathrm{MINCH}$ were respectively quantified in $99 \%$ and $23 \%$ of the samples above the LOQ. The highest readings were observed at $34.9 \mu \mathrm{g} / 1$ for $\mathrm{OH}-\mathrm{MINCH}$ and at $34.8 \mu \mathrm{g} / \mathrm{l}$ for oxo-MINCH.

\subsection{Intake calculated from biomonitoring data}

Using medians and $95^{\text {th }}$ percentiles of the metabolite concentrations in urine, we back-calculated a "typical" and "high" total daily intake for our study population. The methods were described in detail elsewhere [3-5]. These estimates are given in Table 4. Regarding the total intake calculated from biomonitoring data, "high" intake levels were seen for DiNP (14.1 $\mu \mathrm{g} / \mathrm{kg}$ b.w.) and DEHP (11.9 $\mu \mathrm{g} / \mathrm{kg} \mathrm{b.w.).}$

\subsection{Comparison with toxicological values}

The "typical" and "high" total daily intake and daily inhaled and ingested (house dust) amounts reported in our study were compared with the estimated tolerable daily intake (TDI) recommended by scientific institutions.

With regard to phthalates, TDI values were determined by the European Food Safety Agency and by the World Health Organization. A TDI for DINCH was determined from the no observed adverse effect level (NOAEL) of $100 \mathrm{mg} / \mathrm{kg} \mathrm{b.w}$. for renal effects and the application of an uncertainty factor of 100, resulting in a TDI of $1,000 \mu \mathrm{g} / \mathrm{kg}$ b.w. Additionally, Bhat et al. (2014) [9] derived an oral reference dose of $700 \mu \mathrm{g} / \mathrm{kg}$ b.w. for thyroid hypertrophy/hyperplasia in adults rats exposed in utero. 
Table 4: Overall intake of phthalates and DINCH in $\mu \mathrm{g} / \mathrm{kg}$ b.w.

\begin{tabular}{|c|c|c|c|c|}
\hline Substance & \multicolumn{2}{|c|}{ Total daily intake } & $\begin{array}{c}\text { TDI- } \\
\text { value }\end{array}$ & $\begin{array}{c}\text { Reference of TDI- } \\
\text { value }\end{array}$ \\
\hline & "typical" & "high" & & \\
\hline DEP & 0.9 & 6.7 & 500 & WHO 2003 [6] \\
\hline DnBP & 1.3 & 4.9 & 10 & EFSA 2005 [7] \\
\hline DiBP & 1.8 & 6.2 & 10 & EFSA 2005 [7]* \\
\hline BzBP & 0.4 & 3.0 & 500 & EFSA 2005 [7] \\
\hline DEHP & 3.3 & 11.9 & 50 & EFSA 2005 [7] \\
\hline DiNP & 2.2 & 14.1 & 150 & EFSA 2005 [7] \\
\hline & & & & \\
\hline DINCH & 0.5 & 2.8 & 1000 & EFSA 2006 [8] \\
\hline
\end{tabular}

*DiBP has the same toxicity as DnBP; therefore, a similar TDI was assumed.

Compared with the above-mentioned TDI values recommended by scientific institutions, the share of the "high" total intake scenario was $62 \%$ for DiBP, $49 \%$ for DnBP, 24\% for DEHP, 9\% for DiNP, and 0.3\% for DINCH. For BzBP and DEP, only $0.6 \%$ and $1.3 \%$ of the TDI was reached.

\section{References}

[1] Fromme, H., Lahrz, T., Kraft, M., Fembacher, L., Mach, C., Dietrich, S., Burkardt, R., Völkel, W. \& Göen, T., Organophosphate flame retardants and plasticizers in the air and dust in German daycare centers and human biomonitoring in visiting children (LUPE 3). Environ Int, 71, pp. 158-163, 2014.

[2] Fromme, H., Lahrz, T., Kraft, M., Fembacher, L., Dietrich, S., Sievering, S., Burghardt, R., Schuster, R., Bolte, G. \& Völkel, W., Phthalates in German daycare centers: Occurrence in air and dust and the excretion of their metabolites by children (LUPE 3). Environ Int, 61, pp. 64-72, 2013.

[3] Koch, H.M., Wittassek, M., Brüning, T., Angerer, J. \& Heudorf, U., Exposure to phthalates in 5-6 years old primary school starters in Germany - A human biomonitoring study and a cumulative risk assessment. Int $J$ Hyg Environ Health, 214, pp. 188-195, 2011.

[4] Koch, H.M., Schütze, A., Pälmke, C., Angerer, J., Brüning, T. Metabolism of the plasticizer and phthalate substitute diisononyl-cyclohexane-1,2dicarboxylate (DINCH $\left.{ }^{\circledR}\right)$ in humans after single oral doses. Arch Toxicol, 87, pp. 799-806, 2013.

[5] Fromme, H., Gruber, L., Schuster, R., Schlummer, M., Kiranoglu, M., Bolte, G., Völkel, W., 2013. Phthalate and di-(2-ethylhexyl) adipate (DEHA) intake by German infants based on the results of a duplicate diet study and biomonitoring data (INES 2). Food Chem Toxicol, 53, pp. 272-280, 2013. 
[6] WHO (World Health Organization), 2003. Diethyl Phthalate. Concise International Chemical Assessment Document 52, Geneva, 2003. Available at: http://www.who.int/ipcs/publications/cicad/en/cicad52.pdf.

[7] EFSA (European Food Safety Authority), Opinion of the Scientific Panel on food additives, flavourings, processing aids and materials in contact with food (AFC) on a request related to a $10^{\text {th }}$ list of substances for food contact materials. EFSA J, 273, pp. 1-26, 2005.

[8] EFSA (European Food Safety Authority), Opinion of the Scientific Panel on Food Additives, Flavourings, Processing Aids and Materials in Contact with Food (AFC) on a request related to a $12^{\text {th }}$ list of substances for food contact materials. EFSA J, 395 to 401, pp. 1-21, 2006.

[9] Bhat, VS, Durham, JL, Ball, GL, English, JC. Derivation of an oral reference dose (RfD) for the nonphthalate alternative plasticizer 1,2-cyclohexane dicarboxylic acid, di-isononyl ester (DINCH), J Toxicol Environ Health, Part B: Crit Rev, 17, pp. 63-94, 2014. 